\title{
Production of Rosuvastatin Calcium Nanoparticles Using Gas Antisolvent Technique
}

\author{
Experimental and Optimization
}

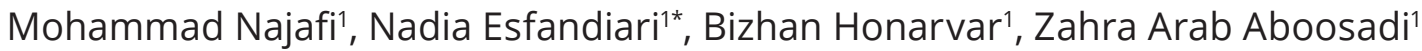 \\ 1 Department of Chemical Engineering, Marvdasht Branch, Islamic Azad University, 73711-13119 Marvdasht, Iran \\ *Corresponding author, e-mail: esfandiari_n@miau.ac.ir
}

Received: 09 June 2020, Accepted: 14 August 2020, Published online: 22 June 2021

\begin{abstract}
The activity of pharmaceutical substances crucially depends on the bioavailability of the substances. The bioavailability of drugs in body and their rate of dissolution in the biological fluids are increased if the particle size is decreased. In the present paper, the Gas Anti-Solvent (GAS) method was used to lower the size of rosuvastatin particles. The effects of temperature (313-338 K), pressure (105-180 bar) and initial solute concentration (20-60 mg/ml) were evaluated by Response Surface Methodology (RSM). The optimum initial solute concentration, temperature and pressure were found to be $20 \mathrm{mg} / \mathrm{ml}, 313 \mathrm{~K}$ and 180 bar, respectively which resulted in the minimum particle size. Furthermore, the particles were characterized by Differential Scanning Calorimetry (DSC), Dynamic Light Scattering (DLS), Fourier Transform Infrared (FTIR) spectroscopy, scanning electron microscopy (SEM), and X-Ray Diffraction (XRD). The analyses showed that the rosuvastatin particles $(60.3 \mathrm{~nm})$ precipitated by GAS process become significantly smaller than the initial particles $(45.8 \mu \mathrm{m})$.
\end{abstract}

Keywords

response surface methodology, supercritical fluid technology, dimethyl sulfoxide, rosuvastatin calcium (ROSCa), nanoparticle

\section{Introduction}

In the pharmaceutics, the insolubility or weak solubility of many drugs in the biological media results in the limited bioavailability, and at the low doses, the therapeutic response is poor [1]. It has been estimated that more than $60 \%$ of pharmaceutical drugs have poor water solubility. A major challenge in the pharmaceutics is that the drugs are weakly soluble in water. The weak solubility of a drug may also lead to the low dissolution characteristics which may bring about limited bioavailability as well as reduced therapeutic efficacy [2]. In addition, the size of drug particle is a limiting factor contributing to the low bioavailability of the compounds with the weak solubility. The more the surface area, the higher the interaction with a solvent, and as a result, the more the solubility $[1,2]$. In the biological media, the dissolution rate of drugs can be improved using the micronization method to resolve the above problems.

There are several methods developed for improving the rate of dissolution in the drugs weakly soluble in the water, including the salt formation [3], surfactant-assisted solubilization $[4,5]$, particle size reduction [6, 7], micro emulsion [8], self-emulsification [9], rapid dissolving tablets [10], complexation [11] and solid dispersion [12, 13]. Moreover, many conventional methods such as grinding, sieving, re-crystallization with evaporation of solvent, and milling spray drying, which can be employed for increasing the dissolution rate and reducing the particle size. During the mechanical treatment, the products may be degraded in the high temperatures and when subjected to the toxic solvents. It is however difficult to achieve the favorable size and distribution of particles using the conventional methods [14, 15].

To transcend the disadvantages of traditional processes, the supercritical fluid technology can be utilized. Carbon dioxide is the most commonly used supercritical fluid, because it possesses the properties including the nontoxicity, low critical pressure and temperature (73.8 bar and $304.55 \mathrm{~K}$ ), relatively high purity, low cost, chemical stability and non-inflammability [16-19]. The methods such as Rapid Expansion of Supercritical Solutions (RESS), anti-solvent 
processes (Gas Anti-Solvent (GAS)), Supercritical AntiSolvent (SAS), Aerosol Solvent Extraction System (ASES), Solution Enhanced Dispersion (SEDS) by supercritical fluids and Particles from Gas-Saturated Solutions/Suspensions (PGSS) use supercritical fluids to make fine particles [14, 15, 20-23]. The GAS technique has been used to obtain the particles of submicron sizes in a variety of drugs including the aspirin [24], ampicillin [18, 25], 5-Fluorouracil [19, 26] and phenanthrene [27].

In the developed countries, the fatalities are primarily caused by Coronary Heart Disease (CHD), and hyperlipidemia is a major risk factor which can be modified to CHD. In the clinical trials, it has been found that the risk of cardiovascular deaths can be lowered with the decrease in the plasma cholesterol. ROSCa, whose commercial name is Crestor, is a member of a group of drugs known as statins or HMG-CoA reductase which is chemically known as 3-hydroxy-3-methylglutaryl-coenzyme A. This drug is commonly used to treat hyperlipidemia [28]. As the first phase in the biosynthesis of cholesterol, this enzyme is used for the catalysis of the HMG-CoA conversion to mevalonate. Furthermore, ROSCa has been employed to reduce bad cholesterol (such as TG and LDL) and to enhance the good cholesterol (HDL) of the blood [29]. It has been used as a synthetic drug to lower the lipid and to treat the diseases such as benign prostatic hyperplasia, osteoporosis, atherosclerosis, triglyceridemia, dyslipidemia, familial hyperlipidemia and Alzheimer's disease [29].

Based on the biopharmaceutical classification, ROSCa is a member of class 2 (low solubility-high permeability) drugs due to its crystalline nature [29, 30]. It is slightly soluble in water and has low oral bioavailability of about $20 \%$ [31]. In addition, ROSCa has a weak solubility in supercritical carbon dioxide (molar fraction solubility $3.00 \times 10^{-6}$ to $2.44 \times 10^{-4}$ at pressure of $121.6-354.6$ bar and temperature of 308-348 K) [32]. The mole fraction of crystalline ROSCa is soluble in water ranging from $5.40 \times 10^{-6}$ to $1.40 \times 10^{-5}$ at atmospheric pressure and temperatures of 298.15-318.15 K [33].

To the best of authors' knowledge, the formation of ROSCa nanoparticles by GAS has not yet been studied in literature. The purpose of this research is hence to produce ROSCa nanoparticles to increase their dissolution rate. In this study, the Response Surface Methodology (RSM) was applied along with the Central Composite Design (CCD) to describe the optimum conditions for reducing the particle size. The effect of different parameters (initial concentration of solute, temperature and pressure) on the size of ROSCa particles was investigated. Furthermore, the Fourier
Transform Infrared spectroscopy (FTIR) analysis, X-Ray Diffraction (XRD), Differential Scanning Calorimetry (DSC), and Scanning Electron Microscopy (SEM) were used to characterize the products and raw materials.

\section{Materials and methods}

\subsection{Materials}

Rosuvastatin calcium (CAS Number 147098-20-2) as solid drug with $98.7 \%$ purity was obtained from Alborz Bulk Pharmaceutical Company (Tehran, Iran). The applied solute was dimethyl sulfoxide (DMSO) with CAS Number of 67-68-5 and purity of $99.9 \%$, Sigma-Aldrich chemicals which was employed without any further purification. Carbon dioxide $\left(\mathrm{CO}_{2}\right)$ with $99.998 \%$ purity and CAS Number of 124-38-9 was prepared from Abughaddareh Company (Shiraz, Iran). The molecular structure of ROSCa used in this study are listed in Fig. 1.

\subsection{Methods}

\subsubsection{Experimental procedure}

GAS process was used to recrystallize the solid compounds that are not dissolved in a supercritical fluid. In GAS process, the dissolution of solute is done in a liquid organic solvent using a gas as an antisolvent for the solute. The gaseous antisolvent can be $\mathrm{CO}_{2}$. The $\mathrm{CO}_{2}$ dissolves into the liquid solution and causes volume expansion. Because of the antisolvent property of dissolved $\mathrm{CO}_{2}$, the solute is precipitated from the solution. In order to achieve a homogeneous distribution of antisolvent in the liquid solution, the $\mathrm{SC}-\mathrm{CO}_{2}$ is rapidly inserted to the solution to close the pressure chamber. According to the volume of cell $(100 \mathrm{ml})$, by increasing the gas concentration in solution and expanding the solution volume, the particle is precipitated. The temperature, pressure and initial concentration of solute are effective parameters on the reduction of particles size. These parameters can control the particle size distribution of the product and the particles with narrower size distribution can be produced $[25,33,34]$.

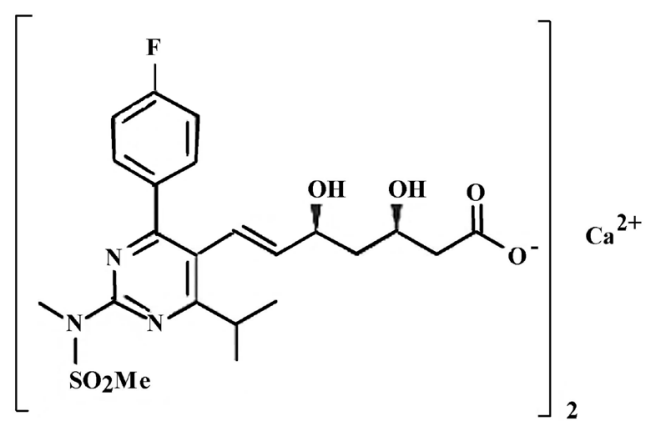

Fig. 1 Molecular structure of ROSCa 
As can be observed in Fig. 2, the system contains gas cylinders, filter, refrigerator, pump (Haskel), oven (Memert), cell, back pressure (Drasstar), micrometer valve (Swagelok), sampler. In this work, ROSCa was initially dissolved in different concentration (between $20-60 \mathrm{mg} / \mathrm{ml}$ ) in an organic solvent (DMSO) in a glass vial. This solution was placed in the precipitation cell and the precipitator temperature was then raised until the experimental temperature. A high-pressure pump was used to pressurize the carbon dioxide to the required pressure. After reaching the experimental temperature and pressure, the pump was turned off and the solution was stored in the precipitator until the saturation of supercritical $\mathrm{CO}_{2}$ with ROS for $30 \mathrm{~min}$. The particles were precipitated in sinter metal filter. The DMSO was removed from the particles at a constant flow rate $(3 \mathrm{~g} / \mathrm{min})$ of $\mathrm{CO}_{2}$ for $60 \mathrm{~min}$. Finally, the system was depressurized and the sample was filter-collected, and stored for further analysis. Particles were found to be dry in all reported cases [33]. The process parameters and levels are presented in Table 1.

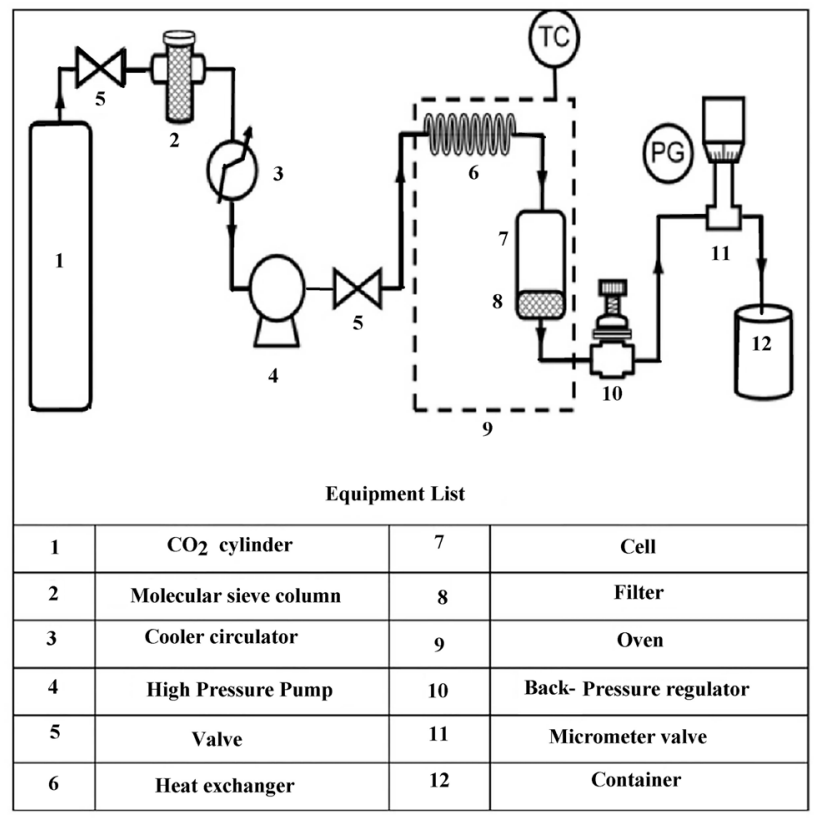

Fig. 2 Process flow diagram of experimental apparatus for Gas method.

Table 1 Variable and their levels used to Central Composite experimental design.

\begin{tabular}{lccccc}
\hline Parameters & Level 1 & Level 2 & Level 3 & Level 4 & Level 5 \\
\hline $\begin{array}{l}\text { Pressure (bar); } x_{1} \\
\begin{array}{l}\text { Solute } \\
\text { concentration } \\
(\mathrm{mg} / \mathrm{mL}) ; x_{2}\end{array}\end{array}$ & 105 & 120 & 143 & 165 & 180 \\
\begin{tabular}{l} 
Temperature $(\mathrm{K}) ; x_{3}$ \\
\hline
\end{tabular} & 313 & 318 & 326 & 333 & 338 \\
\hline
\end{tabular}

\subsubsection{Particle characterization}

In this study, characterization tests for ROSCa nanoparticles included the Dynamic Light Scattering (DLS), Scanning Electron Microscopy (SEM), Differential Scanning Calorimetry (DSC), Fourier Transform Infrared (FTIR) spectroscopy, and X-Ray Diffraction (XRD).

\section{Scanning Electron Microscopy (SEM)}

SEM (TESCAN, VEGA 3, Czech Republic) was conducted for the both processed and unprocessed ROSCa particles to explore the size distribution, average particle size, and particle morphology. The particles were connected on top of the SEM aluminum stubs to the carbon tape for the analysis, and then, using the sputter coater, they were coated with gold.

\section{X-Ray Diffraction (XRD)}

To analyze the ROSCa crystallinity, XRD (XRD; Philips $X^{\prime}$ pert Pro MPD) was conducted for $2 \theta=10-80^{\circ}$ and $1 \mathrm{deg} / \mathrm{min}$ scanning rate using the copper anode as a radiation source $(k=1.54 \AA)$.

\section{Fourier Transform Infrared spectroscopy (FTIR)}

The potassium bromide pellet technique was used to record the FTIR spectra of ROS by FTIR (Perkin Elmer, RX1, Germany) for the 400-4000 $\mathrm{cm}^{-1}$ wavenumber at room temperature.

\section{Differential Scanning Calorimetry (DSC)}

For thermal analysis, DSC (DSC, 404 F3 Pegasus from Netzsch; Germany) was done using $7 \mathrm{mg}$ of the sample placed in an aluminum pan, which was sealed using a reference sealed empty pan. The samples were heated with the $10 \mathrm{~K} / \mathrm{min}$ scanning rate at $298.15-523.15 \mathrm{~K}$ temperature.

\section{Dynamic Light Scattering (DLS)}

The measurement of hydrodynamic diameter of particles was done using the DLS (NANOPHOX; Sympatec GmbH System-Partikel-Technik) and was validated by comparing to the particle size obtained from the SEM images. The analysis was performed after dissolving $5 \mathrm{mg}$ of ROS in $1 \mathrm{ml}$ of deionized water.

\subsubsection{Experimental design (CCD) for nanoparticles production via GAS}

The Response Surface Methodology (RSM) is used along with the Central Composite Design (CCD) as a statistical and mathematical technique to obtain the optimum conditions for determining the particle size as small as possible. This method is widely used in supercritical processes [35-42]. The CCD was employed in this paper for each of the three independent variables in five levels and 
six axial points (with \pm 1.68 axial distance for orthogonal design) with six replicates in center points to study the impact of process factors on the morphology and size of the precipitated ROSCa particles.

Based on a CCD where the parameters were coded in five levels, namely $-\alpha,-1,0,+1$ and $+\alpha$, as presented on Table 2. A total of $N=2^{k}+2 k+6$ experiments were obtained for the four parameters, where $k$ is the number of parameters $(k=3)$, i.e., the entire design involved 20 experimental runs with six center points, eight factorial points (8), eight axial points $(2 \times 3)$ and six replicated center points, according to CCD [35-38].

The independent variables were $x_{1}, x_{2}$ and $x_{3}$ representing pressure; initial solute concentration and temperature, respectively. The DLS was used to obtain the mean particle size $\left(x_{50}\right)$. The system behavior can be expressed by a second-order polynomial equation $[43,44]$ :

$$
\begin{aligned}
& Y=\beta_{0}+\beta_{1} x_{1}+\beta_{2} x_{2}+\beta_{3} x_{3}+\beta_{11} x_{1}^{2}+\beta_{22} x_{2}^{2}+\beta_{33} x_{3}^{2} \\
& +\beta_{12} x_{1} x_{2}+\beta_{13} x_{1} x_{3}+\beta_{23} x_{2} x_{3}+\varepsilon,
\end{aligned}
$$

where $Y$ denotes the predicted response, $x_{1}, x_{2}$ and $x_{3}$ are the input variables; $\beta_{0}$ is constant; $\beta_{1}, \beta_{2}$ and $\beta_{3}$ are the liner coefficients; $\beta_{11}, \beta_{22}$ and $\beta_{33}$ are the quadratic coefficients; $\beta_{12}, \beta_{13}$

Table 2 The independent variables for GAS process along with

\begin{tabular}{|c|c|c|c|c|c|}
\hline Run & $\begin{array}{c}P \\
\text { (bar) }\end{array}$ & $\begin{array}{c}\text { solute } \\
\text { concentration } \\
(\mathrm{mg} / \mathrm{ml})\end{array}$ & $\begin{array}{c}T \\
(\mathrm{~K})\end{array}$ & $\begin{array}{c}\text { Particle size } \\
\text { (nm) }\end{array}$ & $\begin{array}{c}\text { Predicted } \\
\text { value } \\
(\mathrm{nm})\end{array}$ \\
\hline 1 & 105 & 40 & 326 & $156.4 \pm 9.8$ & 159.14 \\
\hline 2 & 143 & 20 & 326 & $90.4 \pm 5.8$ & 87.37 \\
\hline 3 & 143 & 40 & 326 & $95.6 \pm 7.4$ & 100.03 \\
\hline 4 & 120 & 52 & 333 & $167.8 \pm 6.2$ & 168.90 \\
\hline 5 & 165 & 28 & 333 & $59.8 \pm 7.3$ & 65.75 \\
\hline 6 & 143 & 40 & 338 & $103.9 \pm 11.9$ & 99.70 \\
\hline 7 & 143 & 40 & 326 & $97.3 \pm 5.9$ & 100.03 \\
\hline 8 & 180 & 40 & 326 & $65.7 \pm 6.8$ & 58.86 \\
\hline 9 & 120 & 52 & 318 & $153.2 \pm 12.5$ & 150.15 \\
\hline 10 & 143 & 40 & 326 & $100.5 \pm 11.3$ & 100.03 \\
\hline 11 & 165 & 28 & 318 & $63.2 \pm 4.8$ & 65.00 \\
\hline 12 & 143 & 40 & 326 & $102.1 \pm 8.7$ & 100.03 \\
\hline 13 & 120 & 28 & 318 & $105.9 \pm 5.1$ & 106.02 \\
\hline 14 & 143 & 60 & 326 & $146.5 \pm 7.3$ & 145.43 \\
\hline 15 & 143 & 40 & 326 & $103.2 \pm 6.5$ & 100.03 \\
\hline 16 & 143 & 40 & 313 & $83.2 \pm 8.3$ & 83.30 \\
\hline 17 & 143 & 40 & 326 & $100.8 \pm 11.9$ & 100.03 \\
\hline 18 & 165 & 52 & 318 & $79.9 \pm 6.4$ & 83.22 \\
\hline 19 & 120 & 28 & 333 & $118.5 \pm 10.4$ & 118.08 \\
\hline 20 & 165 & 52 & 333 & $87.9 \pm 8.8$ & 90.68 \\
\hline
\end{tabular}
experimental data and predicted CCD.

Temperature and Pressure uncertainties were $0.1 \mathrm{~K}$ and 1 bar. and $\beta_{23}$ represent interaction coefficients and $\varepsilon$ denotes the noise or error [45, 46]. The Design-Expert software (version 7.0.0, Stat-Ease Inc., Minneapolis, USA) was used for the analysis of variance (ANOVA), including $\left(R^{2}\right)$, adjusted $R^{2}$, predicted $R^{2}$ and $F$-values and for the regression and the graphical representation of obtained data.

Statistical testing of the model was performed with Fisher test to obtain the mathematical relationship between input and output parameters. To examine the goodness of fit of the model, a test for significance of regression model was performed and ANOVA is applied to the response data and the value $p<0.05$ is considered as significant. The determination coefficients, $R^{2}$, and their adjusted value, $R^{2}$ adj., were used to evaluate the fit adequacy of the regression model [39-42].

\section{Results and discussion}

As shown in Table 2, twenty experiments were conducted to study the impact of temperature, pressure and initial concentration of solute on the size and distribution of ROSCa particles obtained from GAS process using the CCD statistical model. The level of independent variables used in this experiment was determined based on preliminary experiments. The original particles had an irregular shape with the $45.8 \mu \mathrm{m}$ average diameter. The experiment results are shown in Table 2.

\subsection{Central composite experimental design and evaluation of the fitted model}

To explore the effect of parameters on the size and distribution of particles, the experiments were carried out at five different operating pressures $(10.5,12,14.3,16.5$ and $18 \mathrm{MPa})$, temperatures $(313,318,326,338$ and $338 \mathrm{~K})$ and initial solute concentrations (40, 45, 53, 60, and $65 \mathrm{mg} / \mathrm{ml}$ ). The CCD method was used to determine the optimal conditions and choose the parameters with the highest impact on the morphology and size of the precipitated ROSCa particles in the GAS process. The Central Composite Design (CCD) was also used to investigate the parameters affecting the size and morphology of the precipitation particles by choosing three parameters and five levels. Table 1 presents the parameters and levels. The structure of CCD design and the experimental results are shown in Table 2, Eq. (2) obtained from the RSM indicates the empirical relationship of the response to the independent variables (in coded units):

$$
\begin{aligned}
& Y=100.03-29.81 x_{1}+17.26 x_{2}+4.88 x_{3}+3.17 x_{1}^{2} \\
& +5.79 x_{2}^{2}-3.02 x_{3}^{2}-6.47 x_{1} x_{2}-2.82 x_{1} x_{3}+1.68 x_{2} x_{3},
\end{aligned}
$$


where $Y$ represents the response (ROSCa particle size) and $x_{1}, x_{2}$ and $x_{3}$ are the coded values of the test (pressure, initial solute concentration and temperature, respectively). The response ranged from 60.3 to $168.9 \mathrm{~nm}$. The analysis of variance (ANOVA) is presented in Table 3. The $F$-value and $P$-(prob) value were used to determine the significance of each coefficient. The "Prob $>F$ " values lower than 0.05 represent the significance of model terms.

The model was found to be significant for the $F$-value of $630.36(p<0.0001)$. From the ANOVA results, pressure $\left(x_{1}\right)$ solute concentration $\left(x_{2}\right)$ and temperature $\left(x_{3}\right)$ were found to have the most significant impacts on the model. The $R^{2}$ ( $R$-square), adjusted $R^{2}$ and predicted $R^{2}$ values were used to check the degree of fit for the quadratic model. In fact, the more the $R^{2}$ and adjusted $R^{2}$ values, the better the proposed model will be fitted to the experimental data. The values of regression coefficient $\left(R^{2}\right)$ and adjusted determination coefficient $\left(R^{2}\right.$ adj) of the model were 0.9893 and 0.9796 , respectively. $R^{2}$ and $R^{2}$ adj represent the goodness of fit for the experimental data. The three-dimensional response surface plots as the graphical representation of the regression equations are presented in Fig. 3 (a)-(c).

Table 3 Analysis of variance (ANOVA) for quadratic model.

\begin{tabular}{|c|c|c|c|c|}
\hline Source & $\begin{array}{l}\text { Sum of } \\
\text { squares }\end{array}$ & $\begin{array}{l}\text { Mean } \\
\text { square }\end{array}$ & $F$-value & Prob $>F$ \\
\hline \multicolumn{5}{|l|}{ Intercept } \\
\hline$x_{1}$ & 12137.63 & 12137.63 & 630.36 & $<0.0001$ \\
\hline$x_{2}$ & 4069.56 & 4069.56 & 211.35 & $<0.0001$ \\
\hline$x_{3}$ & 324.91 & 324.91 & 16.87 & 0.0021 \\
\hline$x_{1} x_{2}$ & 335.40 & 335.40 & 17.42 & 0.0019 \\
\hline$x_{1} x_{3}$ & 63.84 & 63.84 & 3.32 & 0.0986 \\
\hline$x_{2} x_{3}$ & 22.44 & 22.44 & 1.17 & 0.3056 \\
\hline$x_{1}^{2}$ & 144.85 & 144.85 & 7.52 & 0.0207 \\
\hline$x_{2}^{2}$ & 482.56 & 482.56 & 25.06 & 0.0005 \\
\hline$x_{3}^{2}$ & 131.16 & 131.16 & 6.81 & 0.0260 \\
\hline Model & 17749.23 & 1972.14 & 102.42 & $<0.0001$ \\
\hline Residual & 192.55 & 19.25 & & \\
\hline Lack of fit & 150.40 & 30.08 & 3.57 & 0.0945 \\
\hline Pure error & 42.15 & 8.43 & & \\
\hline Total & 17941.78 & & & \\
\hline \multirow[t]{2}{*}{ Quadratic } & PRESS & $\begin{array}{c}\text { Adj } \\
R \text {-Squared }\end{array}$ & $\begin{array}{c}\text { Pred } \\
R \text {-Squared }\end{array}$ & $\begin{array}{c}\text { Adeq } \\
\text { Precision }\end{array}$ \\
\hline & 1218.49 & 0.9796 & 0.9321 & 35.50 \\
\hline
\end{tabular}
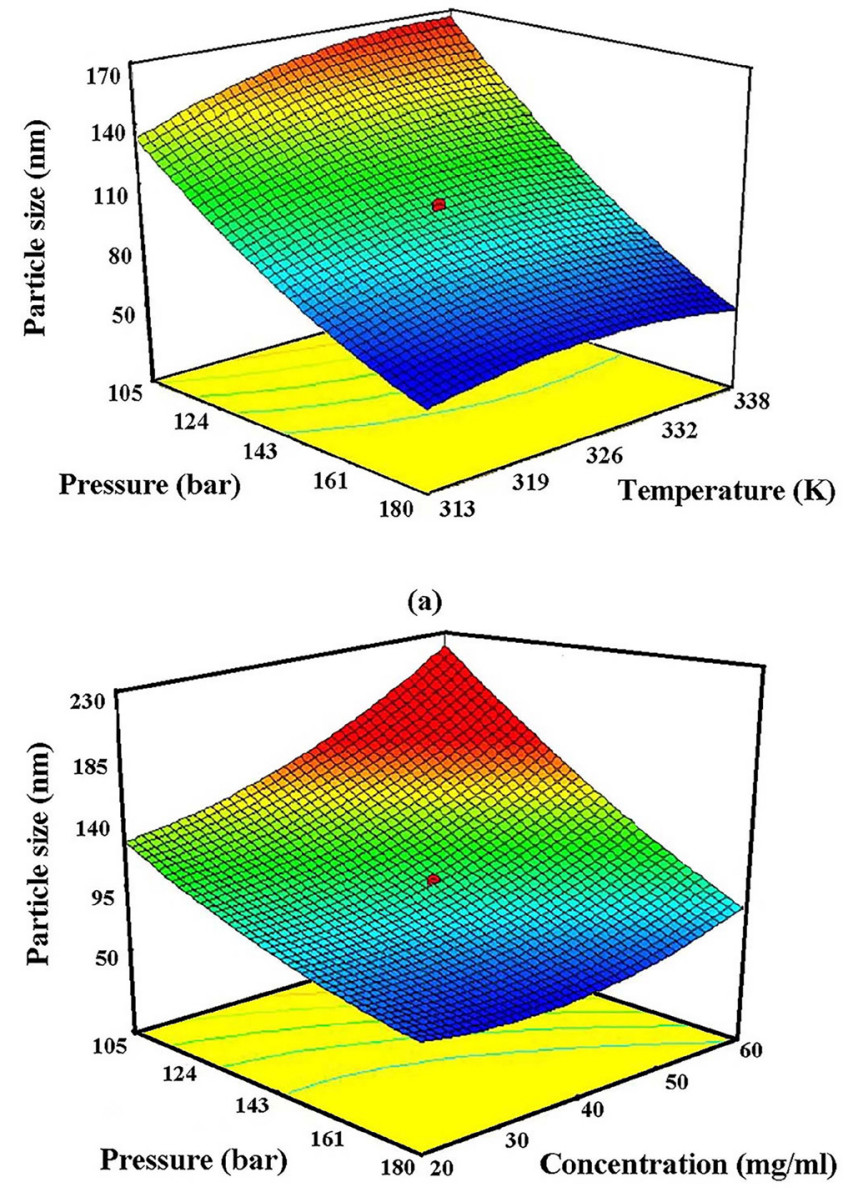

(b)

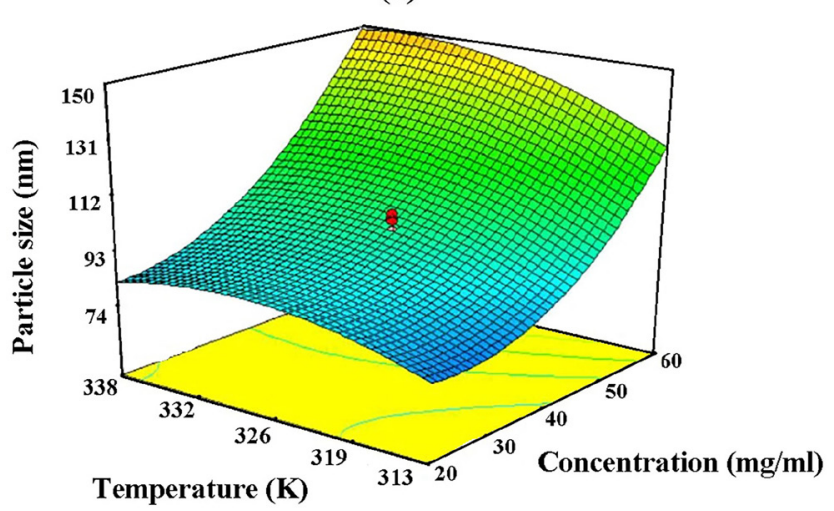

(c)

Fig. 3 The 3D-plots (a) the influence of temperature and pressure on particle size at $40 \mathrm{mg} / \mathrm{ml}$, (b) the influence of solute concentration and pressure on particle size at $326 \mathrm{~K}$ and (c) the influence of solute concentration and temperature on particle size at $114.3 \mathrm{bar}$

\subsection{Effect of operating conditions on particle size 3.2.1 Effect of pressure}

The influence of pressure on the mean particle size and its distribution was investigated at five levels $(105,120$, 
143, 165 and 180 bar). Fig. 3 and Table 2 show that pressure increase in constant temperature $(313 \mathrm{~K}$ ) from 105 to 180 bar reduced the average particle size of ROSCa from 135.8 to $80.3 \mathrm{~nm}$. By elevation of the pressure, carbon dioxide density increased resulting in decline of the intermolecular mean distance of $\mathrm{CO}_{2}$ molecules. Therefore, the solubility of ROS in SC- $\mathrm{CO}_{2}$ was increased, resulting in the greater super-saturation, volume expansion and rate of nucleation. Therefore, an increase in the pressure may result in prevailing of nucleation mechanism and smaller particles of ROSCa. A similar result was achieved by Esfandiari and Ghoreishi [25, 34], Jafari et al. [24] and Chen et al. [47] for 5-Fluorouracil, ampicillin, aspirin and ginkgo ginkgolides, respectively.

\subsubsection{Effect of temperature}

Owing to the effects on the solubility, super-saturation, and nucleation, temperature is an important parameter in the GAS process. Most of the researchers considered the effect of temperature in GAS process, Esfandiari and Ghoreishi [19, 25, 34], Müller et al. [48], Bakhbakhi et al. [27, 49] and Kim et al. [50] to name a few. Therefore, the experiments were conducted at different temperatures within the range of 313-338 $\mathrm{K}$ to assess the effect of temperature on the size and distribution of ROSCa particles.

Fig. 3 and Table 2, show that particle size was increased by temperature rise ranging $313-338 \mathrm{~K}$. By increasing the operating temperature, the ROSCa mean particle size appeared to be large. Particle precipitation with GAS process can be explained by the expansion of volume and decrease of solubility. The solubility of many drugs increases in organic solvent upon the temperature increase. In GAS process, volumetric expansion decreased by the temperature increment. Therefore, saturation and critical super-saturation lines sowed an upward shift. The dominant mechanism is growth and the higher temperature led to higher ROSCa particle size.

\subsubsection{Effect of initial solute concentration}

The initial concentration of solute was found to be an effective factor for controlling the particle size in the GAS process. Therefore, the influence of initial solute concentration was addressed at five levels (20, 28, 40, 52 and $60 \mathrm{mg} / \mathrm{ml}$ ). The results of mean particle size analysis at different concentrations are shown in Fig. 3 and Table 2. If the initial concentration of ROSCa in the solution (DMSO) is reduced, the average size of particles exhibits a decrease. At high concentrations, a larger mean particle diameter was found, and for the lower volume expansion, the nucleation was achieved. Hence, the nucleuses were allowed to grow in a longer period. On the other hand, with decreasing the solute concentrations, solute precipitation occurred at higher volume expansion giving rise to smaller particles. Chen et al. [47], Esfandiari et al. [25] Jafari et al. [24] and Bakhbakhi et al. [49] obtained similar results about the impact of solute concentration on the size distribution and mean particle size of GAS process.

\subsection{Optimum conditions}

The CCD method was used to determine the optimum condition for achieving the smallest particle size by implementing in Design Expert 7.0 software. The determined values were as follows: initial concentration of solute: $20 \mathrm{mg} / \mathrm{ml}$, temperature: $313 \mathrm{~K}$ and pressure: 180 bar. These values were predicted to result in particle size of $60.5 \mathrm{~nm}$. The CCD method was utilized to evaluate the accuracy and validity of the optimization method through the experiments. As such, the average size of particles was $58.6 \mathrm{~nm}$, which was very near to the value obtained from the estimation.

\subsection{Solid state characterization}

According to the FTIR analysis, the GAS process did not influence the ROSCa chemical structure. According to Fig. 4, the FTIR spectra were overlapped for the original and the processed particles, reflecting that there is not any degradable compound in the structure of the processed particles. The FTIR spectra were recorded for the wavenumber ranging from 400 to $4000 \mathrm{~cm}^{-1}$. IR spectrum of ROSCa showed the characteristic peaks at 3337.9, 2968.23, and $1435.48 \mathrm{~cm}^{-1}$ corresponding to the cyclic amines, $\mathrm{C}-\mathrm{H}$ stretching, $\mathrm{C}=\mathrm{O}$ stretching, and $\mathrm{O}-\mathrm{H}$ bending, respectively. A number of researchers reported the same results in their works $[29,51]$.

$\mathrm{XRD}$ is one of the most important analyses for exploring the crystalline characteristics of raw materials, nanoparticles and physical mixture. X-ray diffractograms were taken to determine the structural nature of ROSCa (crystalline or amorphous). X-Ray Diffraction pattern of ROSCa in Fig. 5 (a)-(b) shows diffraction peaks at $2 \theta$ values. The absence of the characteristics peak in processed ROSCa compared to the original particles indicates the transition of the drug structure from crystalline to amorphous. Similar results were obtained by other researchers $[16,17,52]$. Nevertheless, the quite similar structures with the low peak intensities can be detected in the GASprocessed particles as shown in Fig. 5 (b) (with the identical wavelength and diffraction angles). The reduced intensities reflect the decrease in the crystallinity. 


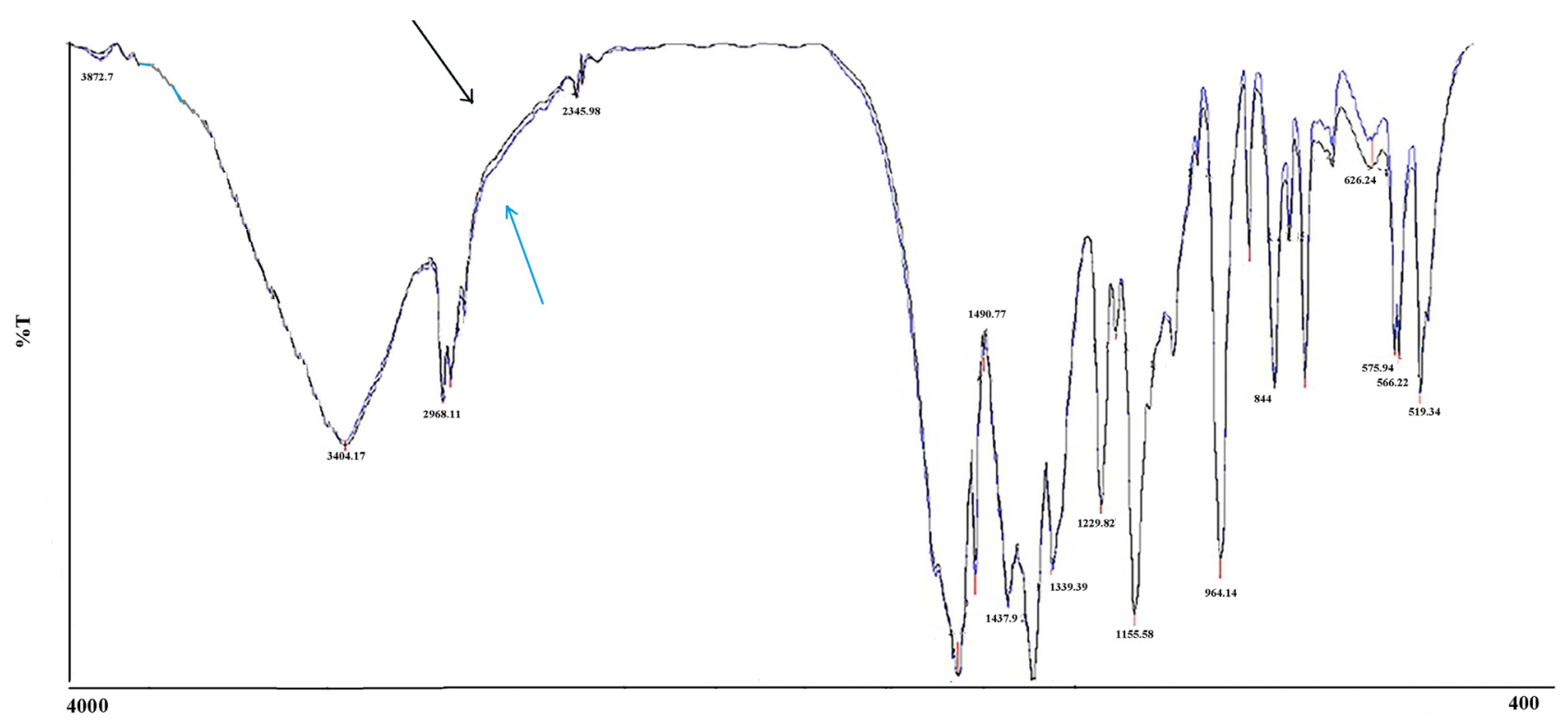

cm -1

Fig. 4 Comparison of the FTIR spectrum of original (Black) and GAS processed ROSCa (Blue)

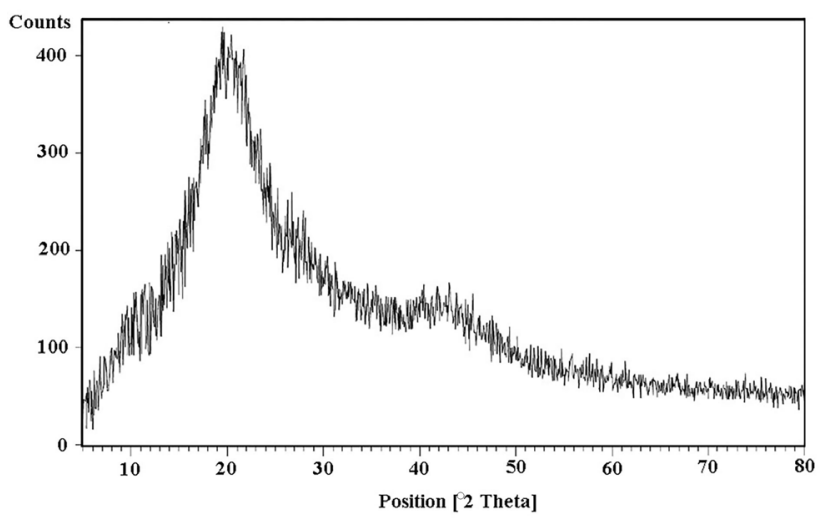

(a)

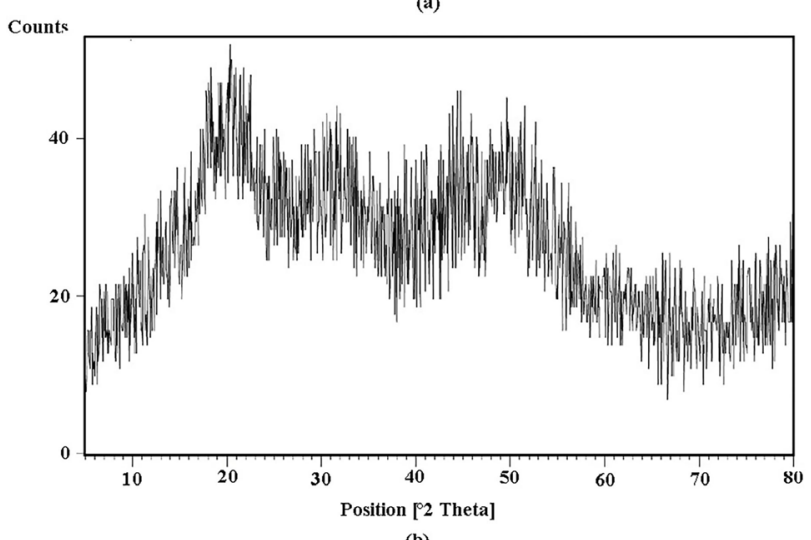

(b)

Fig. 5 XRD patterns of ROSCa before and after the processes: (a) original, (b) GAS processed.

The SEM images displayed in Fig. 6 show the significant reduction in size as a morphological modification of the GAS-processed particles. Note that the shape of original ROS was irregular (see Fig. 6). On the contrary, as illustrated in Fig. 6, the quasi-spherical particles and appropriate Particle Size Distribution (PSD) were generated by the GAS process. PSD of the drug may have remarkable effects on drug product performance (e.g., dissolution, bioavailability, content uniformity, stability, etc.). Many researchers have confirmed that the PSDs of pharmaceutical powders have profound influence on almost every step of manufacturing processes for solid oral dosage forms, including mixing, granulation, drying, milling, blending, coating, encapsulation, and compression [53, 54].

The SEM images of the original and processed particles were verified through the DLS analysis (Fig. 7). According to the DLS results, the nanoparticle size distribution ranged from 60.3 to $168.9 \mathrm{~nm}$, which was more limited than that of the original ROS with the $45.8 \mu \mathrm{m}$ mean. Furthermore, Differential Scanning Calorimetry (DSC) was employed as a supplementary measurement of XRD to characterize the thermal properties of materials. As illustrated in Fig. 8, the melting point of pure ROSCa is $432.05 \mathrm{~K}$ whereas GASprocessed ROSCa has melting point of $427.35 \mathrm{~K}$ showing 4.7 K deviation. Furthermore, decrease in melting enthalpy of DSC in the processed ROSCa particle could be due to changes in crystalline structure and reduction of the particle size. Therefore, it can be suggested that the crystalline nanoparticles were decreased. Several researchers reported similar results in $[29,55,56]$.

\section{Conclusion}

This paper investigated the size and size distribution of GAS-processed ROSCa particles. The impact of process parameters including the temperature, pressure and initial concentration of solute on the ROSCa particles were 


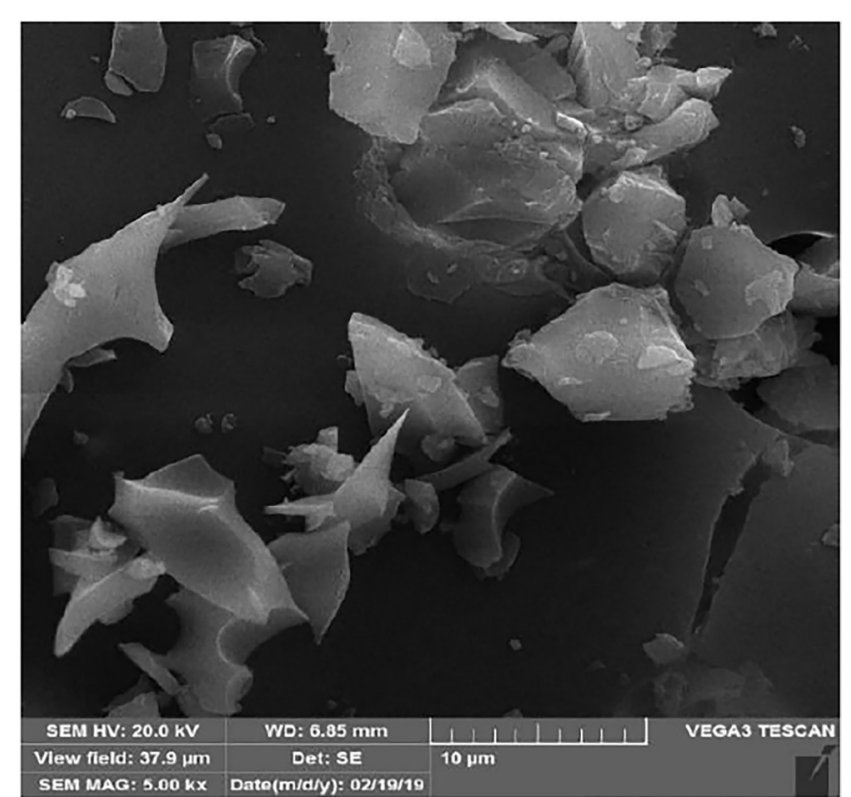

(a)

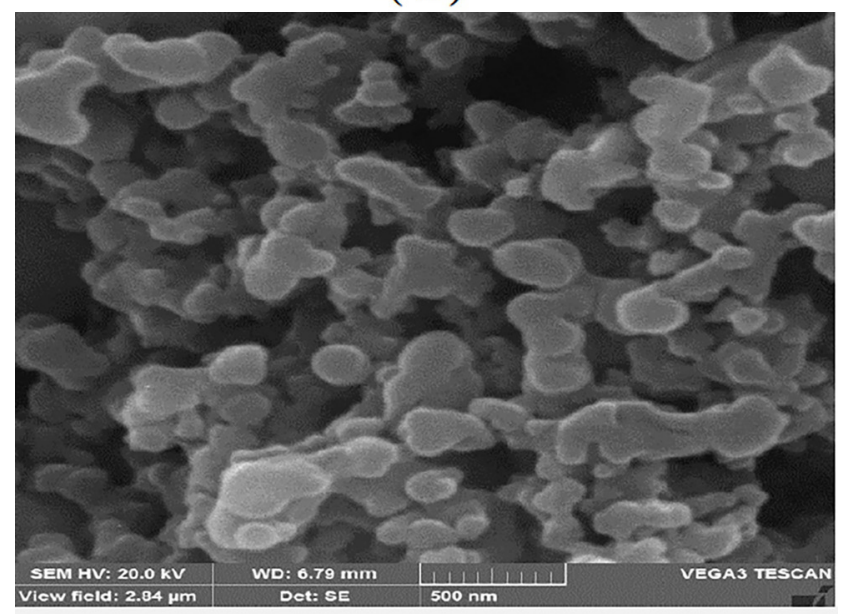

(b)

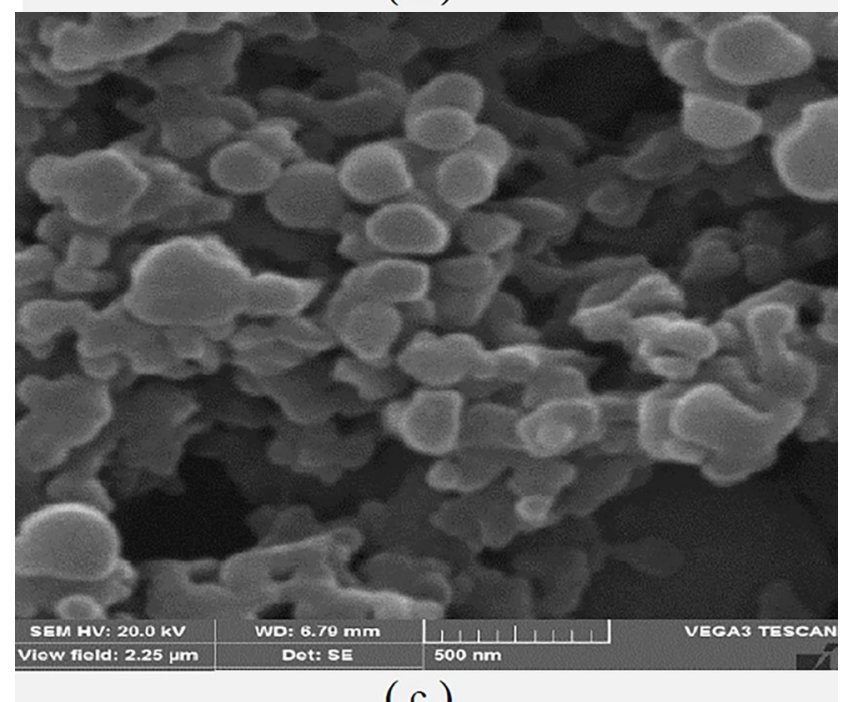

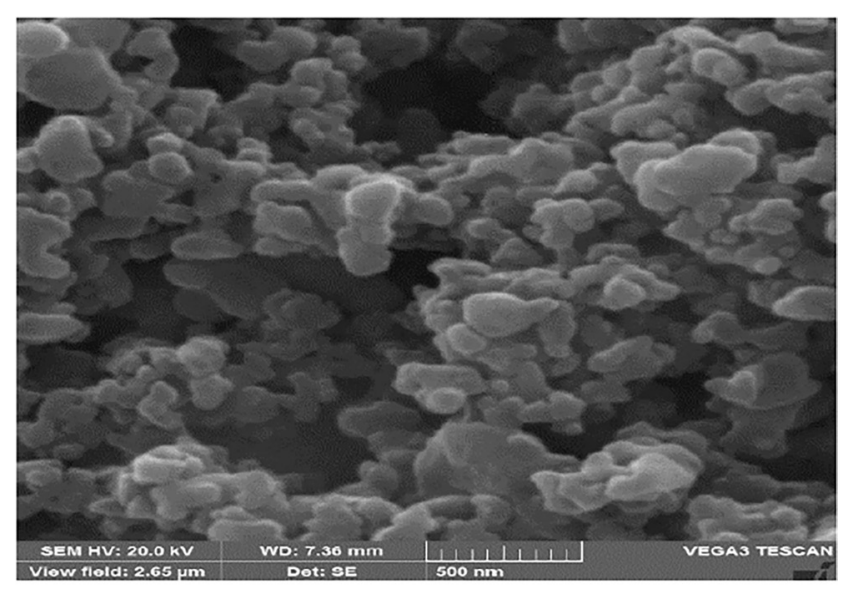

(d)

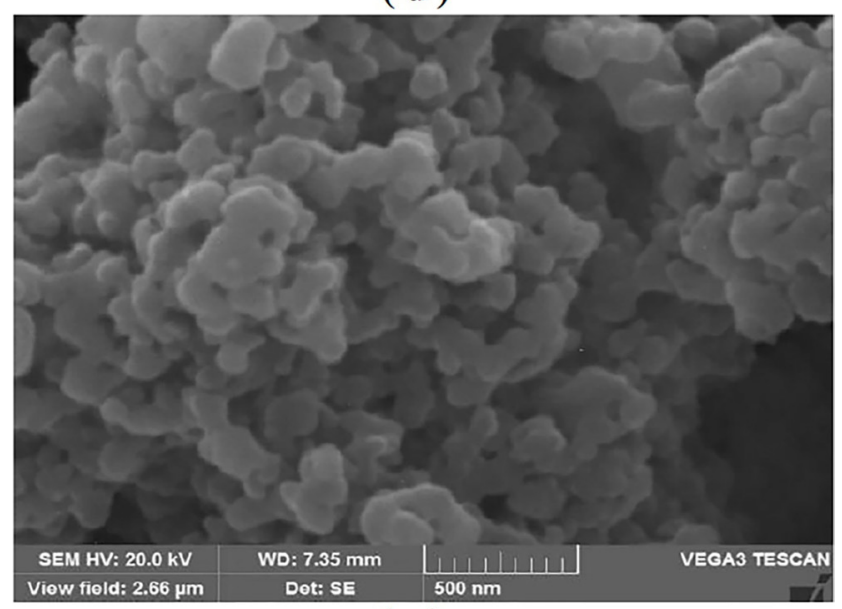

(e)

Fig. 6 SEM images for various cases (based on Table 2): (a) the original ROSCa, (b) Run 6, (c), Run 12, (d) Run19, (e) R-Optimum 


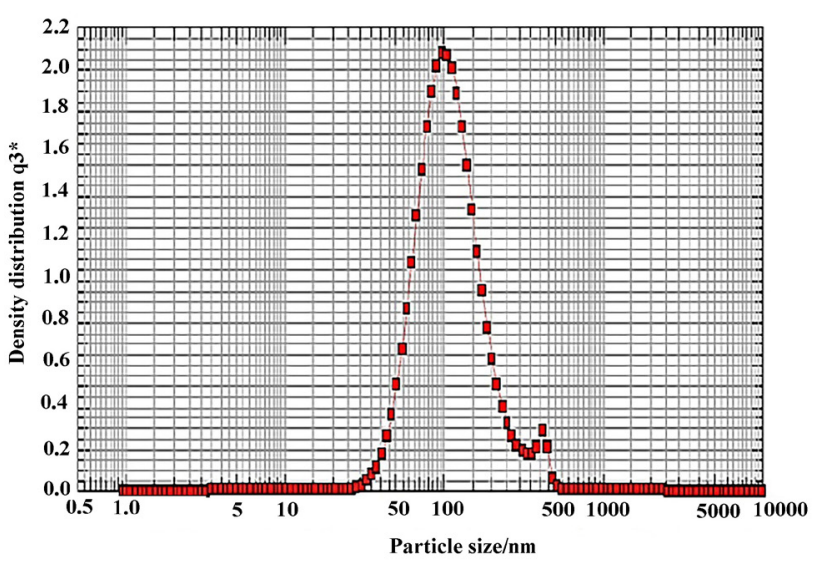

(a)

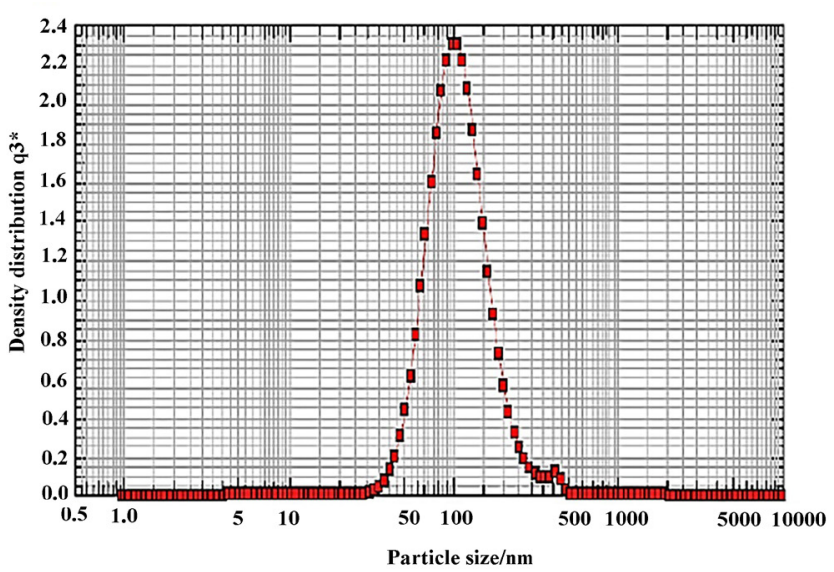

(b)

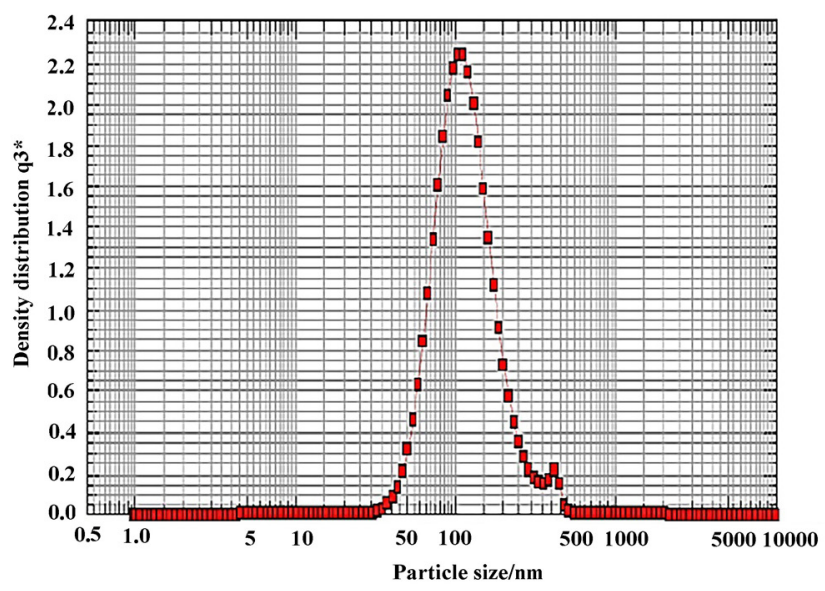

(c)

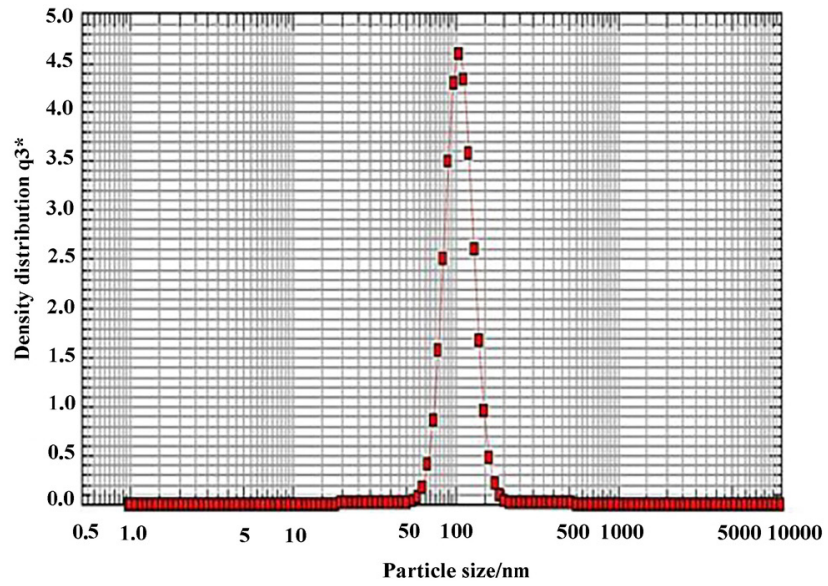

(d)

Fig. 7 DLS graphs for various conditions for GAS process (based on Table 2): (a) Run 6, (b) Run 12, (c) Run 19, (d) R-Optimum

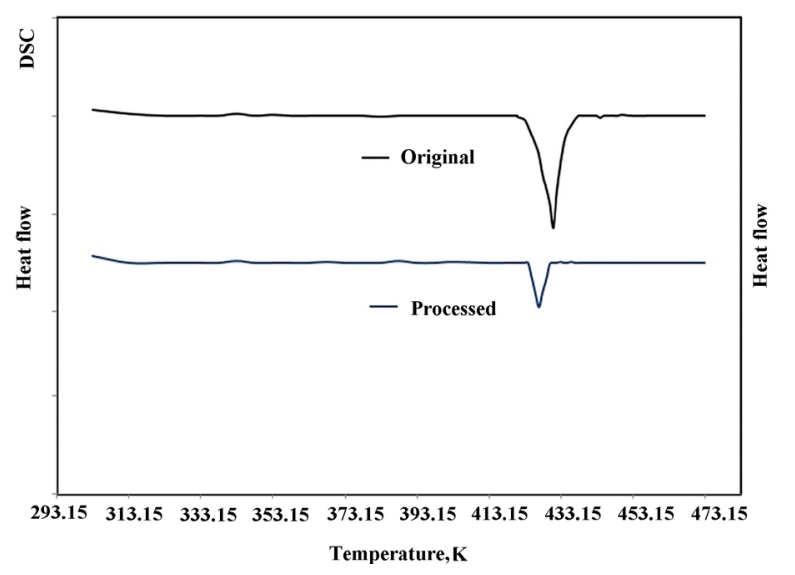

Fig. 8 DSC analysis results of ROSCa before and after the processes: original and GAS processed.

evaluated. Mean size of ROSCa particles was reduced from $45.8 \mu \mathrm{m}$ to $60.3 \mathrm{~nm}$ using the GAS method. The Response Surface Methodology (RSM) was successfully used to optimize the particle size. The optimal values of variables (temperature of $313 \mathrm{~K}$, pressure of 180 bar and initial solute concentration of $20 \mathrm{mg} / \mathrm{ml}$ ) could result in the smallest particles. It was concluded that use of GAS process can decrease the size of ROSCa particles to nanoscale $(60.3 \mathrm{~nm})$. The particle size of ROSCa increased with the rise of initial concentration of solute and temperature. However, pressure increment decreased the ROSCa particles size. Furthermore, the original and precipitated ROSCa particles were analyzed with the SEM, DLS, DSC, XRD, and FTIR. The GAS-precipitated particles had an approximately spherical shape, whereas the unprocessed particles showed irregular forms.

\section{Acknowledgments}

The authors wish to thank Marvdasht University. Also, the authors would like to thank the generous financial support provided by the research deputy of Marvdasht University. 


\section{References}

[1] Krishnaiah, Y. S. R. "Pharmaceutical Technologies for Enhancing Oral Bioavailability of Poorly Soluble Drugs", Journal of Bioequivalence and Bioavailability, 2(2), pp. 28-36, 2010. https://doi.org/10.4172/jbb.1000027

[2] Kumar, A., Sahoo, S. K., Padhee, K., Pal, P., Kochar, S., Satapathy, A., Pathak, N. "Review on Solubility Enhancement Techniques for Hydrophobic Drugs", Pharmacie Globale: International Journal of Comprehensive Pharmacy, 2(3), pp. 1-7, 2011. [online] Available at: https://www.researchgate. net/publication/228712442_REVIEW_ON_SOLUBILITY_ ENHANCEMENT_TECHNIQUES_FOR_HYDROPHOBIC_ DRUGS [Accessed: 08 June 2020]

[3] Ewing, A. V., Wray, P. S., Clarke, G. S., Kazarian, S. G. "Evaluating drug delivery with salt formation: Drug disproportionation studied in situ by ATR-FTIR imaging and Raman mapping", Journal of Pharmaceutical and Biomedical Analysis, 111, pp. 248-256, 2015. https://doi.org/10.1016/j.jpba.2015.03.040

[4] Filippa, M. A., Gasull, E. I. "Ibuprofen solubility in pure organic solvents and aqueous mixtures of cosolvents: Interactions and thermodynamic parameters relating to the solvation process", Fluid Phase Equilibria, 354, pp. 185-190, 2013.

https://doi.org/10.1016/j.fluid.2013.06.032

[5] Chen, X., Fadda, H. M., Aburub, A., Mishra, D., Pinal, R. "Cosolvency approach for assessing the solubility of drugs in poly (vinylpyrrolidone)", International Journal of Pharmaceutics, 494(1), pp. 346-356, 2015.

https://doi.org/10.1016/j.ijpharm.2015.08.016

[6] Xu, J., Luo, K.Q. "Enhancing the solubility and bioavailability of isoflavone by particle size reduction using a supercritical carbon dioxide-based precipitation process", Chemical Engineering Research and Design, 92(11), pp. 2542-2549, 2014.

https://doi.org/10.1016/j.cherd.2014.03.018

[7] Lipinski, C. A., Lombardo, F., Dominy, B. W., Feeney, P. J. "Experimental and computational approaches to estimate solubility and permeability in drug discovery and development settings", Advanced Drug Delivery Reviews, 23(1-3), pp. 3-25, 1997.

https://doi.org/10.1016/S0169-409X(96)00423-1

[8] Chen, Y., Tuo, J., Huang, H., Liu, D., You, X., Mai, J., Song, J., Xie, Y., Wu, C., Hu, H. "Optimized mixed oils remarkably reduce the amount of surfactants in microemulsions without affecting oral bioavailability of ibuprofen by simultaneously enlarging microemulsion areas and enhancing drug solubility", International Journal of Pharmaceutics, 487(1-2), pp. 17-24, 2015. https://doi.org/10.1016/j.ijpharm.2015.03.075

[9] Qureshi, M. J., Mallikarjun, C., Kian, W. G. "Enhancement of solubility and therapeutic potential of poorly soluble lovastatin by SMEDDS formulation adsorbed on directly compressed spray dried magnesium aluminometasilicate liquid loadable tablets: A study in diet induced hyperlipidemic rabbits", Asian Journal of Pharmaceutical Sciences, 10(1), pp. 40-56, 2015. https://doi.org/10.1016/j.ajps.2014.08.003

[10] Seedher, N., Kanojia, M. "Micellar Solubilization of Some Poorly Soluble Antidiabetic Drugs: A Technical Note", AAPS PharmSciTech, 9(2), pp. 431-436, 2008. https://doi.org/10.1208/s12249-008-9057-5
[11] Poon, S. F., Stock, N., Payne, J. E., McGuire, A. R., Stearns, B., Yang, X., Chen, W., Munoz, B., Smith, N. D. "Novel approach to pro-drugs of lactones: water soluble imidate and ortho-ester derivatives of a furanone-based COX-2 selective inhibitor", Bioorganic \& Medicinal Chemistry Letters, 15(9), pp. 2259-2263, 2005. https://doi.org/10.1016/j.bmcl.2005.03.009

[12] Mohanachandran, P., Sindhumol, P., Kiran, T. "Enhancement of solubility and dissolution rate: An overview", International Journal of Comprehensive Pharmacy, 4(11), pp. 1-10, 2010. [online] Available at: http://www.pharmacie-globale. info/index.php?option=com_docman\&amp; task=cat_ view\&amp;gid=40\&amp;Itemid=41 [Accessed: 08 June 2020]

[13] He, Y., Ho, C. "Amorphous Solid Dispersions: Utilization and Challenges in Drug Discovery and Development", Journal of Pharmaceutical Sciences, 104(10), pp. 3237-3258, 2015.

https://doi.org/10.1002/jps.24541

[14] Hiendrawan, S., Veriansyah, B., Tjandrawinata, R. R. "Micronization of fenofibrate by rapid expansion of supercritical solution", Journal of Industrial and Engineering Chemistry, 20(1), pp. 54-60, 2014.

https://doi.org/10.1016/j.jiec.2013.04.027

[15] Yildiz, N., Tuna, Ş., Döker, O., Çalimli, A. "Micronization of salicylic acid and taxol (paclitaxel) by rapid expansion of supercritical fluids (RESS)", The Journal of Supercritical Fluids, 41(3), pp. 440-451, 2007. https://doi.org/10.1016/j.supflu.2006.12.012

[16] Sodeifian, G., Sajadian, S. A. "Utilization of ultrasonic-assisted RESOLV (US-RESOLV) with polymeric stabilizers for production of amiodarone hydrochloride nanoparticles: Optimization of the process parameters", Chemical Engineering Research and Design, 142, pp. 268-284, 2019. https://doi.org/10.1016/j.cherd.2018.12.020

[17] Sodeifian, G., Sajadian, S. A., Ardestani, N. S., Razmimanesh, F. "Production of Loratadine drug nanoparticles using ultrasonic-assisted Rapid expansion of supercritical solution into aqueous solution (US-RESSAS)", The Journal of Supercritical Fluids, 147, pp. 241-253, 2019. https://doi.org/10.1016/j.supflu.2018.11.007

[18] Esfandiari, N., Ghoreishi, S. M. "Optimal thermodynamic conditions for ternary system $\left(\mathrm{CO}_{2}\right.$, DMSO, ampicillin) in supercritical $\mathrm{CO}_{2}$ antisolvent process", Journal of the Taiwan Institute of Chemical Engineers., 50, pp. 31-36, 2015. https://doi.org/10.1016/j.jtice.2014.12.015

[19] Esfandiari, N., Ghoreishi, S. M. "Kinetics modeling of ampicillin nanoparticles synthesis via supercritical gas antisolvent process", The Journal of Supercritical Fluids, 81, pp. 119-127, 2013. https://doi.org/10.1016/j.supflu.2013.05.018

[20] Reverchon, E., De Marco, I., Della Porta, G. "Rifampicin microparticles production by supercritical antisolvent precipitation", International Journal of Pharmaceutics, 243(1-2), pp. 83-91, 2002. https://doi.org/10.1016/S0378-5173(02)00261-2

[21] Yeo, S.-D., Kiran, E. "Formation of polymer particles with supercritical fluids: A review", The Journal of Supercritical Fluids, 34(3), pp. 287-308, 2005. https://doi.org/10.1016/j.supflu.2004.10.006 
[22] Matos, R. L., Lu, T., Prosapio, V., McConville, C., Leeke, G., Ingram, A. "Coprecipitation of curcumin/PVP with enhanced dissolution properties by the supercritical antisolvent process", Journal of $\mathrm{CO}_{2}$ Utilization, 30, pp. 48-62, 2019. https://doi.org/10.1016/j.jcou.2019.01.005

[23] Franco, P., Reverchon, E., De Marco, I. "Zein/diclofenac sodium coprecipitation at micrometric and nanometric range by supercritical antisolvent processing", Journal of $\mathrm{CO}_{2}$ Utilization, 27, pp. 366-373, 2018. https://doi.org/10.1016/j.jcou.2018.08.015

[24] Jafari, D., Yarnezhad, I., Nowee, S. M., Baghban, S. H. N. "Gas-Antisolvent (GAS) Crystallization of Aspirin Using Supercritical Carbon Dioxide: Experimental Study and Characterization", Industrial \& Engineering Chemistry Research, 54(14), pp. 3685-3696, 2015. https://doi.org/10.1021/ie5046445

[25] Esfandiari, N., Ghoreishi, S. M. "Ampicillin Nanoparticles Production via Supercritical $\mathrm{CO}_{2}$ Gas Antisolvent Process", AAPS PharmSciTech, 16(6), pp. 1263-1269, 2015. https://doi.org/10.1208/s12249-014-0264-y

[26] Esfandiari, N., Ghoreishi, S. M. "Kinetic Modeling of the Gas Antisolvent Process for Synthesis of 5-Fluorouracil Nanoparticles", Chemical Engineering \& Technology, 37(1), pp. 73-80, 2014. https://doi.org/10.1002/ceat.201300431

[27] Bakhbakhi, Y., Rohani, S., Charpentier, P. A. "Micronization of Phenanthrene Using the Gas Antisolvent Process. 1. Experimental Study and Use of FTIR", Industrial \& Engineering Chemistry Research, 44(19), pp. 7337-7344, 2005.

https://doi.org/10.1021/ie050206e

[28] Istvan, E. S., Deisenhofer, J. "Structural Mechanism for Statin Inhibition of HMG-CoA Reductase", Science, 292(5519), pp. 1160-1164, 2001.

https://doi.org/10.1126/science.1059344

[29] Sarfraz, R. M., Ahmad, M., Mahmood, A., Minhas, M. U., Yaqoob, A. "Development and Evaluation of Rosuvastatin Calcium Based Microparticles for Solubility Enhancement: An In Vitro Study", Advances in Polymer Technology, 36(4), pp. 433-441, 2017.

https://doi.org/10.1002/adv.21625

[30] Amidon, G. L., Lennernäs, H., Shah, V.P., Crison, J. R. "A Theoretical Basis for a Biopharmaceutic Drug Classification: The Correlation of in Vitro Drug Product Dissolution and in Vivo Bioavailability", Pharmaceutical Research, 12(3), pp. 413-420, 1995.

https://oi.org/10.1023/A:1016212804288

[31] Schachter, M. "Chemical, pharmacokinetic and pharmacodynamic properties of statins: an update", Fundamental \& Clinical Pharmacology, 19(1), pp. 117-125, 2005. https://doi.org/10.1111/j.1472-8206.2004.00299.x

[32] Hojjati, M., Yamini, Y., Khajeh, M., Vatanara, A. "Solubility of some statin drugs in supercritical carbon dioxide an d representing the solute solubility data with several density-based correlations", The Journal of Supercritical Fluids, 41(2), pp. 187-194, 2007. https://doi.org/10.1016/j.supflu.2006.10.006

[33] Esfandiari, N. "Production of micro and nano particles of pharmaceutical by supercritical carbon dioxide", The Journal of Supercritical Fluids, 100, pp. 129-141, 2015. https://oi.org/10.1016/j.supflu.2014.12.028
[34] Esfandiari, N., Ghoreishi, S. M. "Synthesis of 5-Fluorouracil nanoparticles via supercritical gas antisolvent process", The Journal of Supercritical Fluids, 84, pp. 205-210, 2013. https://doi.org/10.1016/j.supflu.2013.10.008

[35] Sodeifian, G., Ardestani, N. S., Sajadian, S. A., Moghadamian, K. "Properties of Portulaca oleracea seed oil via supercritical fluid extraction: Experimental and optimization", The Journal of Supercritical Fluids, 135, pp. 34-44, 2018. https://doi.org/10.1016/j.supflu.2017.12.026

[36] Sodeifian, G., Sajadian, S. A., Ardestani, N. S. "Experimental optimization and mathematical modeling of the supercritical fluid extraction of essential oil from Eryngium billardieri: Application of simulated annealing (SA) algorithm", The Journal of Supercritical Fluids, 127, pp. 146-157, 2017. https://doi.org/10.1016/j.supflu.2017.04.007

[37] Sodeifian, G., Sajadian, S. A. "Investigation of essential oil extraction and antioxidant activity of Echinophora platyloba DC. using supercritical carbon dioxide", The Journal of Supercritical Fluids, 121, pp. 52-62, 2017.

https://doi.org/10.1016/j.supflu.2016.11.014

[38] Sodeifian, G., Sajadian, S. A., Ardestani, N. S. "Supercritical fluid extraction of omega-3 from Dracocephalum kotschyi seed oil: Process optimization and oil properties", The Journal of Supercritical Fluids, 119, pp. 139-149, 2017.

https://doi.org/10.1016/j.supflu.2016.08.019

[39] Sodeifian, G., Ghorbandoost, S., Sajadian, S. A., Ardestani, N. S. "Extraction of oil from Pistacia khinjuk using supercritical carbon dioxide: Experimental and modeling", The Journal of Supercritical Fluids, 110, pp. 265-274, 2016. https://doi.org/10.1016/j.supflu.2015.12.004

[40] Sodeifian, G., Sajadian, S. A., Ardestani, N. S. "Evaluation of the response surface and hybrid artificial neural network-genetic algorithm methodologies to determine extraction yield of Ferulago angulata through supercritical fluid", Journal of the Taiwan Institute of Chemical Engineers, 60, pp. 165-173, 2016. https://doi.org/10.1016/j.jtice.2015.11.003

[41] Sodeifian, G., Sajadian, S. A., Ardestani, N. S. "Extraction of Dracocephalum kotschyi Boiss using supercritical carbon dioxide: Experimental and optimization", The Journal of Supercritical Fluids, 107, pp. 137-144, 2016. https://doi.org/10.1016/j.supflu.2015.09.005

[42] Sodeifian, G., Sajadian, S. A., Ardestani, N. S. "Optimization of essential oil extraction from Launaea acanthodes Boiss: Utilization of supercritical carbon dioxide and cosolvent", The Journal of SupercriticalFluids, 116 pp. 46-56, 2016. https://doi.org/10.1016/j.supflu.2016.05.015

[43] Sathyamoorthy, N., Magharla, D., Chintamaneni, P., Vankayalu, S. "Optimization of paclitaxel loaded poly ( $\varepsilon$-caprolactone) nanoparticles using Box Behnken design", Beni-Suef University Journal of Basic and Applied Sciences, 6(4), pp. 362-373, 2017. https://doi.org/10.1016/j.bjbas.2017.06.002

[44] Zhao, K., Cheng, Y., Liu, H., Yang, C., Qiu, L., Zeng, G., He, H. "Extractive desulfurization of dibenzothiophene by a mixed extractant of $N, N$-dimethylacetamide, $N, N$-dimethylformamide and tetramethylene sulfone: optimization by Box-Behnken design", RSC Advances, 5(81), pp. 66013-66023, 2015. https://doi.org/10.1039/C5RA12305D 
[45] Montgomery, D. C. "Design and Analysis of Experiments", John Wiley \& Sons, Hoboken, NJ, USA, 2017.

[46] Sodeifian, G., Sajadian, S. A., Honarvar, B. "Mathematical modelling for extraction of oil from Dracocephalum kotschyi seeds in supercritical carbon dioxide", Natural Product Research, 32(7), pp. 795-803, 2017.

https://doi.org/10.1080/14786419.2017.1361954

[47] Chen, K., Zhang, X., Pan, J., Zhang, W., Yin, W. "Gas antisolvent precipitation of Ginkgo ginkgolides with supercritical $\mathrm{CO}_{2}$ ", Powder Technology, 152(1-3), pp. 127-132, 2005.

https://doi.org/10.1016/j.powtec.2005.01.009

[48] Müller, M., Meier, U., Kessler, A., Mazzotti, M. "Experimental Study of the Effect of Process Parameters in the Recrystallization of an Organic Compound Using Compressed Carbon Dioxide as Antisolvent", Industrial \& Engineering Chemistry Research, 39(7), pp. 2260-2268, 2000.

https://doi.org/10.1021/ie990828y

[49] Bakhbakhi, Y., Charpentier, P. A., Rohani, S. "Experimental study of the GAS process for producing microparticles of beclomethasone-17, 21-dipropionate suitable for pulmonary delivery", International Journal of Pharmaceutics, 309(1-2), pp. 71-80, 2006. https://doi.org/10.1016/j.ijpharm.2005.11.008

[50] Kim, S.-J., Lee, B.-M., Lee, B.-C., Kim, H.-S., Kim, H., Lee, Y.-W. "Recrystallization of cyclotetramethylenetetranitramine (HMX) using gas anti-solvent (GAS) process", The Journal of Supercritical Fluids, 59, pp. 108-116, 2011. https://doi.org/10.1016/j.supflu.2011.07.016

[51] Alshora, D. H., Haq, N., Alanazi, F. K., Ibrahim, M. A., Shakeel, F. "Solubility of rosuvastatin calcium in different neat solvents at different temperatures", The Journal of Chemical Thermodynamics, 94, pp. 230-233, 2016.

https://doi.org/10.1016/j.jct.2015.11.019
[52] Sodeifian, G., Sajadian, S. A., Daneshyan, S. "Preparation of Aprepitant nanoparticles (efficient drug for coping with the effects of cancer treatment) by rapid expansion of supercritical solution with solid cosolvent (RESS-SC)", The Journal of Supercritical Fluids, 140, pp. 72-84, 2018. https://doi.org/10.1016/j.supflu.2018.06.009

[53] Shekunov, B. Y., Chattopadhyay, P., Tong, H. H. Y., Chow, A. H. L. "Particle Size Analysis in Pharmaceutics: Principles, Methods and Applications", Pharmaceutical Research, 24(2), pp. 203-227, 2007. https://doi.org/10.1007/s11095-006-9146-7

[54] Sun, Z., Ya, N., Adams, R. C., Fang, F. S. "Particle Size Specifications for Solid Oral Dosage Forms: A Regulatory Perspective", American Pharmaceutical Review, 13(4), pp. 68-73, 2010. [online] Available at: https://www.americanpharmaceuticalreview.com/ Featured-Articles/36779-Particle-Size-Specifications-for-SolidOral-Dosage-Forms-A-Regulatory-Perspective/ [Accessed: 08 June 2020]

[55] Sodeifian, G., Ardestani, N. S., Sajadian, S. A., Panah, H. S. "Experimental measurements and thermodynamic modeling of Coumarin7 solid solubility in supercritical carbon dioxide: Production of nanoparticles via RESS method", Fluid Phase Equilibria, 483, pp. 122-143, 2019. https://doi.org/10.1016/j.fluid.2018.11.006

[56] Thakur, R., Gupta, R. B. "Rapid Expansion of Supercritical Solution with Solid Cosolvent (RESS-SC) Process: Formation of Griseofulvin Nanoparticles", Industrial \& Engineering Chemistry Research, 44(19), pp. 7380-7387, 2005. https://doi.org/10.1021/ie050417j 